\title{
Q
}

\section{Role of physics lecture demonstrations in conceptual learning}

\author{
Kelly Miller, ${ }^{1, *}$ Nathaniel Lasry, ${ }^{2}$ Kelvin $\mathrm{Chu},{ }^{3}$ and Eric Mazur ${ }^{1}$ \\ ${ }^{1}$ Department of Physics and Division of Engineering and Applied Sciences, Harvard University, \\ Cambridge, Massachusetts 02138, USA \\ ${ }^{2}$ Department of Physics, John Abbott College, Montreal, Quebec H9X 3L9, Canada \\ ${ }^{3}$ Department of Physics, University of Vermont, Burlington, Vermont 05405, USA
}

(Received 30 May 2013; published 17 September 2013)

\begin{abstract}
Previous research suggests that students' prior knowledge can interfere with how they observe and remember lecture demonstrations. We measured students' prior knowledge in introductory mechanics and electricity and magnetism at two large universities. Students were then asked to predict the outcome of lecture demonstrations. We compare students' predictions before having seen the demonstration to what they report having seen both right after the demonstration and several weeks later. We report four main findings. First, roughly one out of every five observations of a demonstration is inconsistent with the actual outcome. Second, students who understand the underlying concepts before observing the demonstration are more likely to observe it and remember it correctly. Third, students are roughly $20 \%$ (23\%) more likely to observe a demonstration correctly if they predict the outcome first, regardless of whether the prediction is correct or not. Last, conceptual learning is contingent on the student making a correct observation. This study represents an initial step towards understanding the disconnect reported between demonstrations and student learning.
\end{abstract}

DOI: 10.1103/PhysRevSTPER.9.020113

PACS numbers: 01.50.My, 01.40.gb, 01.40.Ha

\section{INTRODUCTION}

Lecture demonstrations are an integral part of introductory physics courses. Instructors see demonstrations as a way to help students develop an intuitive understanding of the world and remember concepts [1-3]. Instructors often view demonstrations as a way to liven up lectures $[3,4]$. However, demonstrations may not be effective in promoting student learning and may even be counterproductive [5-7]. How much students learn from demonstrations depends on the way the demonstration is presented [8]. There are two objectives to this paper. The first is to examine the role of demonstrations in conceptual learning. The second is to provide useful insights into increasing the effectiveness of lecture demonstrations.

Students entering science classrooms have various preconceptions of how the physical world works. Students may have some conceptions that are unstable and highly context dependent [9-11] while other conceptions may be robust and appear to be in conflict with the concepts to be learned [12]. Conceptual learning of physics is often very difficult, particularly in instances when students have strongly held conceptions.

Elicit, confront, resolve is an effective instructional approach that promotes conceptual learning [13]. This

\footnotetext{
*kmiller@harvard.edu

Published by the American Physical Society under the terms of the Creative Commons Attribution 3.0 License. Further distribution of this work must maintain attribution to the author(s) and the published article's title, journal citation, and DOI.
}

approach first exposes students to a situation where they are likely to make a mistake, if they hold a given misconception. It then elicits their ideas about the situation. Students' misconceptions are then confronted by exposing them to the error and helping them realize inconsistencies in their thinking. Inconsistencies are resolved by working through the reasoning required to reconcile their existing understanding with the new concept. In the context of demonstrations, the "elicit, confront, resolve" cycle is better known as "predict, observe, explain" (POE) [14]. Students' misconceptions are elicited through their prediction of the outcome of a demonstration they are likely to find surprising. These misconceptions are confronted when students observe the demonstration and resolved when students are asked to explain their observation. The documented effectiveness of interactive lecture demonstrations [15] is based on the POE strategy.

Prediction making plays an important role in student learning. Couch et al. compared three different ways to present demonstrations: (1) observe, in which students passively watch the demonstration; (2) predict, in which students' predictions are recorded before they watch the demonstration; and (3) discuss, in which students record their predictions, observe the demonstration, and then discuss the outcome with one another. No significant differences were found between students who observed the demonstrations and students who had not seen them at all. Students who were first asked to predict the outcome of the demonstration were significantly more likely to correctly identify the outcome of the demonstration [8]. For demonstrations to be effective, students must first predict the outcome. 
Some studies of demonstrations have examined the relationship between students' predictions and what they observe during a demonstration. Students often see what they predicted, even when this observation is different from what the instructor is actually demonstrating [16-18]. Hence, predictions are necessary, but they may not be sufficient.

We study the role of predictions on conceptual learning. We examine how students' predictions affect what they report having seen during a demonstration. We also examine how student predictions affect what they recall as the outcome of the demonstration at the end of the semester.

We find that roughly one out of every five observations (18\%) of a demonstration is inconsistent with the actual outcome. Furthermore, conceptual learning depends on students accurately observing the outcome of the demonstration, regardless of whether their initial prediction is correct or incorrect. Contrary to previous studies [16-18], students who make an incorrect prediction are as likely to accurately report the outcome of the demonstration as those who make a correct prediction. This may be due to the surprisingly high number of students who predict correctly but then fail to accurately report the outcome of the demonstration. Indeed, though $20 \%$ of students who predict incorrectly also report the incorrect outcome, $16 \%$ of students who predict correctly also report the outcome incorrectly. We identify two situations that are associated with successfully observing and remembering a demonstration: (1) first predicting the outcome before seeing the demonstration (regardless of whether the prediction is correct or not) and (2) having a basic prior understanding of the concepts underlying the demonstration.

\section{METHODS}

Students in this study were registered in one of two introductory physics courses for nonmajors at two large research institutions: a mechanics class for engineering students $(N=201)$ and an electricity and magnetism class for engineering and premedical students $(N=91)$. Lecture demonstration data were collected from 22 different demonstrations in these two classes (10 from the mechanics class and 12 from the electricity and magnetism class). Throughout the semester, the instructor presented demonstrations during the lectures as a regular part of the course.

While the analysis presented represents results pooled from both classes, each class was first analyzed separately. We combined the results after establishing identical trends in each. Students in both classes were told to follow the same procedure when it came to each demonstration. Table I presents a summary of this procedure. Some students chose not to predict the outcome of the demonstration. In their response to the outcome question, these students reported being present and having seen the demonstration in class. We compare these to students who did make a prediction.
TABLE I. Summary of the data collection procedure.

\begin{tabular}{llc}
\hline \hline & Measurement instrument & Timing \\
\hline In class & $\begin{array}{l}\text { (1) 2-4 conceptual questions } \\
\text { (2) Predict question }\end{array}$ & Before demo \\
& (3) $2-4$ conceptual questions & After demo \\
Online & (4) Question on demo outcome & 1 day after demo \\
& (5) Question on demo outcome & End of semester \\
\hline \hline
\end{tabular}

We examined students' predictions to the outcomes of lecture demonstrations and what they report as having observed during the demonstration both directly afterwards and at the end of the semester.

Immediately before and immediately after each demonstration, students were required to answer 2-4 multiplechoice conceptual questions. Pre- and postdemonstration questions were different, but were designed to be of similar difficulty. Both sets of questions were designed to probe students' understanding of the physics underlying each demonstration. To measure conceptual learning, we compare students' performance on the predemonstration questions with their performance on the postdemonstration questions [19]. Responses to both sets of conceptual questions were recorded via a web-based polling system [20] during class.

Students were asked to predict the outcome of a demonstration by responding to a multiple-choice question with choices that spanned the full range of possible outcomes. Students were given a few minutes to think and record their predictions and were told not to discuss with their classmates. Predictions were recorded with the same web-based system in class.

Students were asked what they had observed during the demonstration twice after each demonstration. Right after the lecture students had a day to answer online (1) a multiple-choice question asking what they observed as the outcome of the demonstration and (2) a free-response question asking them to explain their understanding of the physics behind the demonstration. Students who missed the demonstration in class could select I did not see this demonstration, one of the response options for the multiple-choice question. The same two questions were asked again at the end of the semester. We compare what students report having seen after the demonstration to what they remember at the end of the semester.

\section{RESULTS AND DISCUSSION}

Figure 1 shows aggregate results of students' responses to the outcome questions asked after class and at the end of the semester. The average percentage of correct outcomes is shown for students who (1) failed to make a prediction, (2) predicted correctly, and (3) predicted incorrectly. We confirmed that the population in each group was equivalent in aptitude by calculating the average final grade for each 


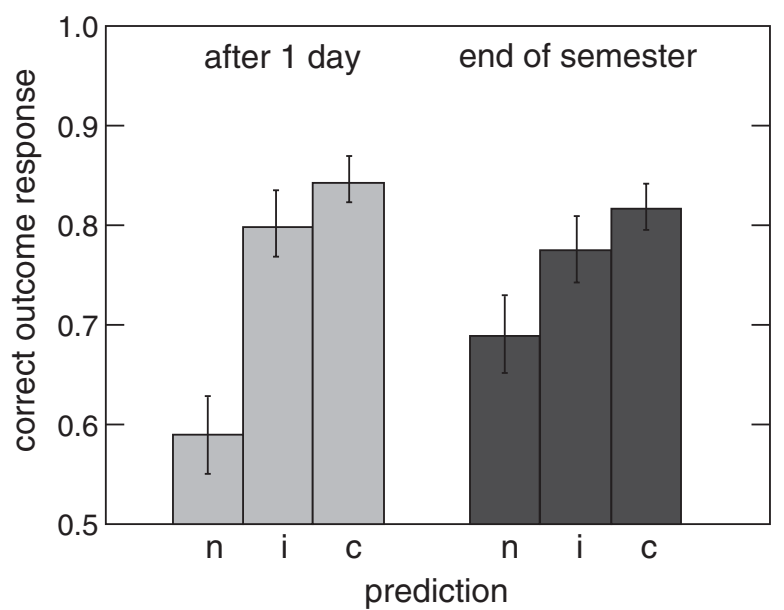

FIG. 1. Average percentage of correct response to the outcome question asked one day after the demonstration (light gray) and at the end of the semester (dark gray), for students who made no prediction (n) or predicted the demonstration correctly (c) or incorrectly (i).

of the no prediction, predict incorrectly, and predict correctly groups, which were $77.6 \%, 78.4 \%$, and $78.8 \%$, respectively. The difference in final grade between the no predict and other two (predict) groups is not significant at the $p<0.05$ level. Using data from the web-based polling system, we determined that students who did not make predictions had answered other questions during the same classes as the demonstrations. In the outcome question after the demonstration, these students did not select the $I$ did not see this demonstration option. Hence, students who did not make a prediction were present during the class and claimed to have seen the demonstration. It is possible that these students did not predict the outcome of the demonstration because they were inattentive when the prediction question was posed, did not know the answer, or simply failed to register their answer in time.

Figure 1 validates previous research that pointed to the importance of having students first predict the outcome of the demonstration [8]. A comparison of the no predict group to the other two (predict) groups indicates that students who predict are significantly more likely to correctly report the outcome of a demonstration, regardless of whether asked within a day of seeing the demonstration or several weeks later. Making a prediction, regardless of whether it is correct or not, appears to play an important role in correctly observing the event and a less important role in remembering it.

Especially noteworthy is that students who predict incorrectly answer the outcome question correctly at approximately the same rate as students who predict correctly. This finding goes against aforementioned studies [16-18] that have suggested students' observations are often in consonance with their incorrect predictions. Surprisingly, a high percentage ( $16 \%$ on average) of students who do predict correctly, still report the outcome of the demonstration incorrectly when asked within one day of the event.

Also of note is the finding that there is no significant difference in the percentage of correct outcome response between the two instances in time (within a day of having seen the demonstration compared to at the end of the semester). Assuming they make a prediction, students who state the outcome correctly in the first place are likely to remember it when asked later in the semester, regardless of whether their prediction was correct or incorrect.

In addition to the role of prediction making, we also looked at students' level of conceptual understanding. Students were grouped according to their performance on the predemonstration conceptual questions. Figure 2 shows how students at different levels of predemonstration conceptual understanding respond to the outcome question within a day of the demonstration and at the end of the semester. Figure 2 compares students at three different levels of performance on these questions: (1) bottom third of the class, (2) middle third of the class, and (3) top third of the class. Students with a strong understanding of the concepts before seeing the demonstration correctly report the outcome at the end of the semester at a significantly higher rate than students who have a weak conceptual understanding. Students whose predemonstration conceptual performance is in the top third of the class correctly report the outcome of the demonstration $21 \%(p<0.001)$ more frequently than students in the bottom third of the class.

To measure the role that demonstrations play in conceptual learning, we compare students' performance on the pre- and postdemonstration conceptual questions. Figure 3 compares the (normalized) postdemonstration conceptual performance of students who responded correctly to the initial outcome question to students who responded

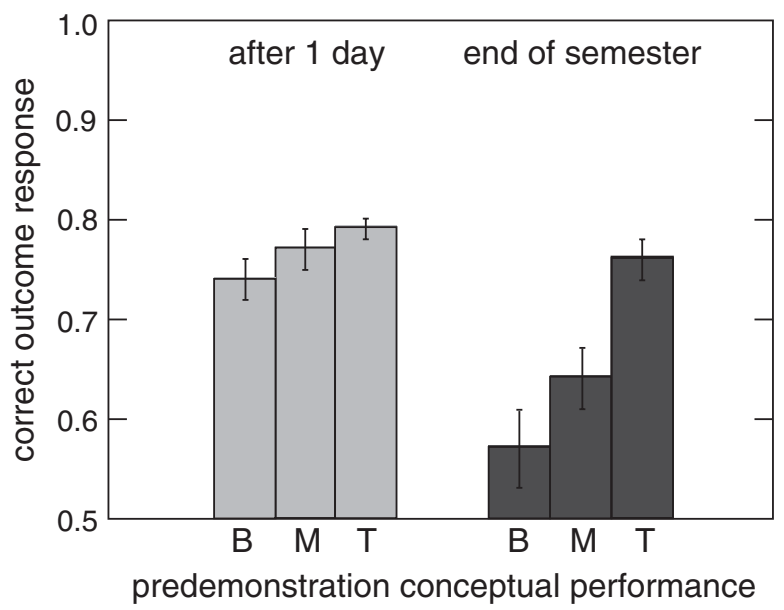

FIG. 2. Average percentage of correct response to the outcome question asked one day after the demonstration (light gray) and at the end of the semester (dark gray), for students at three different levels of performance on the predemonstration conceptual questions: bottom third of the class (B), middle third of the class $(\mathrm{M})$, and top third of the class $(\mathrm{T})$. 


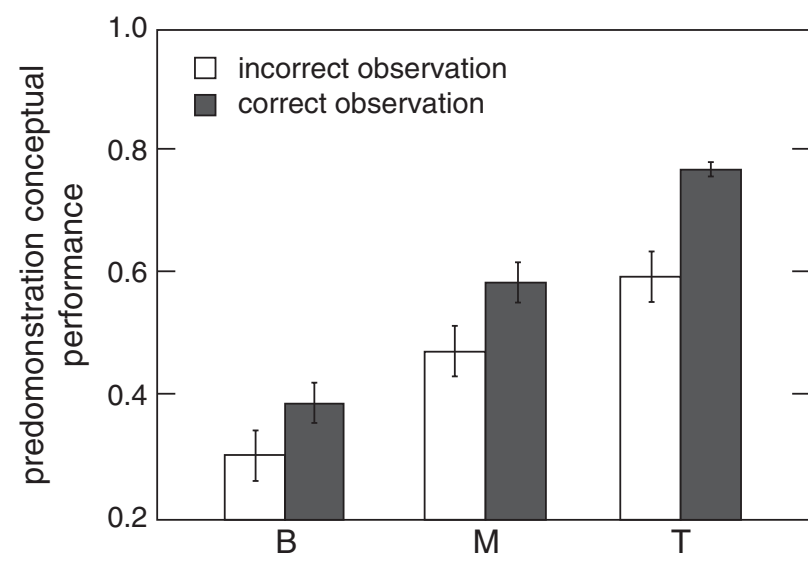

postdemonstration conceptual performance

FIG. 3. Comparison of the postdemonstration conceptual performance for students who responded correctly to the initial outcome question (gray) to students who responded incorrectly (white), for students at three different levels of performance on the predemonstration conceptual questions: bottom third of the class (B), middle third of the class (M), and top third of the class $(\mathrm{T})$.

incorrectly. To control for predemonstration conceptual test performance, we make this comparison within the three different levels of performance on the predemonstration questions.

Students who correctly state the outcome of the demonstration experience significantly higher conceptual learning $(p<0.005)$ than students who do not state the outcome correctly. Within the top third in predemonstration conceptual understanding, students who correctly identify the outcome of the demonstration score $17 \%$ higher on the postdemonstration conceptual test than students who incorrectly identify the outcome of the demonstration.

\section{CONCLUSION}

Our results replicate earlier findings on the importance of having students predict the outcome of a demonstration [8] and lead to three new conclusions. The first is that, when asked within a day of seeing a demonstration, students report an incorrect outcome $18 \%$ of the time, regardless of whether they predict the outcome correctly or incorrectly. The second is that, for a demonstration to lead to conceptual learning, it is important that the student observes it correctly in the first place. Thirdly, students are more likely to observe the demonstration correctly if they (a) make a prediction first and (b) have some conceptual understanding of the underlying physics beforehand. These findings support the importance of having students predict the outcome of a demonstration, regardless of whether they predict correctly or not. Furthermore, demonstrations are most effective in promoting learning when students have at least a basic level of conceptual understanding beforehand. In light of these findings, we recommend that demonstrations be integrated into a learning sequence that helps students develop background knowledge first. These findings support the effectiveness of POE strategies such as interactive learning demonstrations [15], which emphasize both prediction making and conceptual scaffolding of the demonstration.

\section{ACKNOWLEDGMENTS}

Several people contributed to the work described in this paper. N. L conceived of the basic idea for this work. David Hammond helped select the mechanics demonstrations and was an important advisor throughout the project. Julie Schell, Brian Lukoff, and Laura Tucker provided feedback on the manuscript throughout its development.
[1] V. Eaton, C. Overbeck, and R. P. Winch, Wesleyan conference on demonstration lectures, Am. J. Phys. 28, 539 (1960).

[2] J.D. R. Carpenter and R. B. Minnix, The lecture demonstration: Try it, they'll like it, Phys. Teach. 19, 391 (1981).

[3] W. Lewin, For the Love of Physics: From the End of the Rainbow to the Edge of Time-A Journey Through the Wonders of Physics (Simon \& Schuster, New York, 2011).

[4] R. DiStefano, Preliminary IUPP results: Student reactions to inclass demonstrations and to the presentation of coherent themes , Am. J. Phys. 64, 58 (1996).

[5] W. Roth, J. Campbell, B. Keith, and S. Boutonne, Why may students fail to learn from demonstrations? A social practice perspective on learning in physics, J. Res. Sci. Teach. 34, 509 (1997).

[6] D. P. Shepardson, E. B. Moje, A. M. Kennard, and A. M. McClelland, The impact of a science demonstration on children's understandings of air pressure, J. Res. Sci. Teach. 31, 243 (1994).

[7] S. Tobias and R. Hake, Professors as physics students: What can they teach us?, Am. J. Phys. 56, 786 (1988).

[8] C. Crouch, A. Fagen, and J. P. Callan, Classroom demonstrations: Learning tools or entertainment?, Am. J. Phys. 72, 835 (2004).

[9] A. A. diSessa, Toward an epistemology of physics, Cognit. Instr. 10, 105 (1993).

[10] D. Hammer, A. Elby, R. E. Scherr, and E. F. Redish, in A Transfer of Learning from a Modern Multidisciplinary Perspective, edited by J. Mestre (Information Age Publishing, Greenwich, CT, 2005), pp. 89-120.

[11] N. Lasry, S. Rosenfield, H. Dedic, A. Dahan, and O. Reshef, The puzzling reliability of the Force Concept Inventory, Am. J. Phys. 79, 909 (2011). 
[12] S. Vosniadou, X. Vamvakoussi, I. Skopeliti, and S. Vosniadou, International Handbook of Research on Conceptual Change (Routledge, New York, 2008).

[13] L. C. McDermott and E. F. Redish, Resource letter: PER-1: Physics education research, Am. J. Phys. 67, 755 (1999).

[14] R. T. White, Conceptual and conceptional change, Learn. Instr. 4, 117 (1994).

[15] D. Sokoloff and R. Thornton, Using interactive lecture demonstrations to create an active learning environment, Phys. Teach. 35, 340 (1997).

[16] A. B. Champagne, R.F. Gunstone, and L.E. Klopfer, in Cognitive Structure and Conceptual Change, edited by L. H. T. West and A. L. Pines (Academic, Orlando, FL, 1985), pp. 163-187.
[17] R. Gunstone and R. White, Understanding of gravity, Sci. Educ. 65, 291 (1981).

[18] C. R. Hynd, J. Y. McWhorter, V.L. Phares, and C.W. Suttles, The role of instructional variables in conceptual change in high school physics topics, J. Res. Sci. Teach. 31, 933 (1994).

[19] See Supplemental Material at http://link.aps.org/ supplemental/10.1103/PhysRevSTPER.9.020113 for an online appendix with examples of the types of pre- and postconceptual questions that were used to probe students' understanding of the physics underlying the demonstration. Also provided are examples of the demonstrations used in this study.

[20] https://learningcatalytics.com/ 